\title{
Small, But Significant Declines In Crop Productivity On Low Fertility Soils
}

\section{Samantha Ramirez, Ellen Esch and Andrew MacDougall}

Department of Integrative Biology, University of Guelph, Guelph, ON Canada. Faculty supervisor: A. MacDougall

For correspondence, please email: sramirez@uoguelph.ca

\begin{abstract}
Agricultural yields are susceptible to losses during extreme weather events related to climate change, jeopardizing food security. Yield losses may be mediated by underlying quality or variation of agricultural land in soil fertility, topography, drainage, and growing degree days. For instance, crops grown on poor quality land may be more susceptible to the negative consequences of climate variation as compared to crops grown on high quality land. This study investigated yield response for corn, soybeans, and pasture to different land qualities across Ontario from 2011 to 2017. Yield is approximated using the Normalized Difference Vegetation Index (NDVI), which is a satellite-derived measure of biomass production. For three focal crops (soybean, corn, and pasture), the average maximum NDVI and the coefficient of variance (CV) of maximum NDVI were aggregated at a provincial and county scale for each land quality classification. Relatively stable CV values were evident across all land qualities, yet certain counties showed greater variation in productivity on poor quality land suggesting greater susceptibility to extreme weather. Over 7 years, there were small but significant declines in NDVI in response to poor quality land for all three crop types. This suggests that agricultural producers cannot overcome the biophysical limitations of poor quality land on crop yield. Understanding differential crop productivity responses to land quality can help producers mitigate crop losses to climatic variation, thus equally stabilizing food availability.
\end{abstract}

Keywords: agriculture, NDVI, soil fertility, yield

\section{Introduction}

Agricultural crop yields are influenced by a suite of biophysical conditions including soil fertility and characteristics such as water retention and drainage, temperature and precipitation patterns, and crop management techniques. Modern agricultural technologies have sought to minimize the influence of these environmental and edaphic variables on yield. For instance, synthetic fertilizer applications can alleviate soil fertility constraints, and agricultural tilling practices can improve poor soil drainage issues. Synthetic fertilizer applications alone have resulted in yield gains of $20 \%$ between 1985 and 2005 (Deepak et al., 2012). It has previously been tested whether modern management practices can overcome background biophysical influences - generally referred to as "land quality" — on yield, but it remains inconclusive as to whether these practices are sufficient given the lack of research (Lobell et al., 2011; Esch et al., unpublished). Understanding the influence of land quality on agricultural yield is increasingly important given the necessity to double agricultural output by year 2050 (Alexandratos \& Bruinsma, 2012). This is coupled with a growing reliance on marginal—or poor quality — land for crop production (Esch et al., unpublished), particularly as highquality agricultural land becomes scarce (Young, 1999).

In addition, individual crop types may respond differentially to background soil quality or climatic characteristics despite modern agricultural techniques. Mechanistically, the varying crop yield responses may be driven by crop functional traits, where certain functional traits can minimize the negative impact of climate or soil fertility on yield (Tilman et al., 1997; Gastal et al., 2015). For instance, climate change perturbations-including altered temperatures and precipitation patterns - have impacted global maize and wheat yields (decreased by $3.8 \%$ and $5.5 \%$, respectively) while other crops including rice and soybeans have not been impacted (Lobell et al., 2011).

Soil fertility is an essential factor that impacts crop productivity. With respect to soil fertility, legume crops that have symbiotic associations with rhizobia may be less influenced by limitations in soil fertility as compared to crops without the ability to fix atmospheric nitrogen (Gastal et al. 2015). Additionally, crops associated with greater diversity (e.g. pasture lands commonly comprised of mixes of Poaceae and Fabaceae) may be able to leverage biodiversity-function 
relationships to produce greater yields despite poor background soil fertility (Tilman et al., 1997; Schulte et al., 2017). Ecosystems with greater biodiversity have been shown to have greater ecosystem stability and productivity (Tilman, Wedin \& Knops 1997), therefore land cover with greater biodiversity may be less sensitive to limiting biophysical factors such as soil fertility or adverse climatic variation.

The variability of crop yield, in addition to the total yield, may also be affected by land quality. Evidence from the Midwest shows that crops grown on poor quality land have greater susceptibility to yield losses during droughts (Wright \& Wimberly, 2013; Zhu et al. 2018) presumably as a result of soil with lower organic carbon content and thus lower water holding capacity. Thus, interannual yield variability may be larger on poor quality land where growing seasons with droughts or flooding, for example, may have more pronounced negative impacts. Given that crop yield instability can lead to food insecurity (Lobell et al. 2011), this raises the question of whether crop production will be adequately stable in the future, particularly if given a growing reliance on marginal agricultural land.

To investigate total crop yield and variability in crop yield to land quality, we evaluated the normalized difference vegetation index (NDVI) as a proxy for crop productivity across seven land qualities (suitability for agricultural productivity) or three main crops across Ontario, Canada. NDVI measures the photosynthetic capacity of vegetation and can be used as a proxy for agricultural yield (Nguy-Robertson et al. 2012; Johnson 2011; Paruelo et al. 1997). Crop productivity was measured across 7 land quality classes, ranging from low to high suitability for agricultural production (Department of Forestry, 1965). Measurements were taken for 3 common field crops (corn, soybean, pasture) grown over a 7-year period (2011-2017). It was predicted that lower overall NDVI and greater NDVI variability would be associated with poor quality land (Zhu et. al 2018), and that soybean and pasture crops would have less NDVI variability in comparison to corn due to nitrogen fixing and biodiversity functions, respectively. Previous studies have shown correlation between crop yield variability and climate variability (Deepak et al. 2015; Toshichika \& Navin, 2016), along with small-scale effects of soil fertility on crop yield (Vieira \& Gonzalez 2003), yet this study in particular analyzes crop yield response to land quality across the large-scale of Ontario. Understanding how crop yield can vary based on crop type and climate change is important when aiming to optimize crop yield efficiency on variable land quality.

\section{Methods}

\section{Study Design}

This research tested if land quality affects the mean and variability in crop yield (crop stability) for three main crops in Ontario. The Canada Land Inventory (CLI) data obtained from Agriculture and Agri-Food Canada classifies land quality across Canada from a scale of 1 to 7 (Table 1), 1 being the most fertile and 7 being the least fertile (Department of Forestry 1965). Specifically, this study used the CLASS_A feature attribute within the CLI data. CLASS_A classifies land quality across Canada based on soil fertility, agricultural limitations, required conservation practices, and climate (Table 1). Classification of land is based on data collected from air photo interpretation, field surveys and census information. These data are mapped on a 1:250,000 scale (125 $\times 125 \mathrm{~m}$ ) (Statistics Canada 2016). The CLI began in 1963 and took almost two decades to complete with both federal and provincial governments surveying the agricultural capability of Canadian land (Statistics Canada 2016). Despite the date in which this survey began, the soil capability classification is considered still valid and widely used in land operations (AAFC 2013).

Land use, or crop identity, was obtained using the Agriculture and Agri-Food Canada Annual Crop Inventory (ACI) data. Crop type was differentiated using near infrared (NIR) and short-wave infrared (SWIR) band within multitemporal optical data from satellite observations (AAFC 2009). Throughout the growing season, optical images during key crop phonological stages (reproduction, seed development and senescence) identified commonly grown crops. Currently, the ACI method of identifying cropland has an accuracy of at least $85 \%$ at the spatial resolution of $30 \mathrm{~m}$. The ACI began classifying crops across Ontario beginning in 2011, hence the data analysis in this paper likewise starts in 2011. Three core crop types were used in this analysis; corn (Zea mays), soybeans (Glycine max) and pasture (not differentiated, but likely mixes of Poaceae sp. and Fabaceae sp.). These crops were chosen because of their unique functional characteristics and their widespread abundance across Ontario. Soybeans are unique because of their nitrogen-fixing capability that may lessen the effects of land on productivity, whereas corn is equally widespread across Ontario yet lacks the ability to fix nitrogen. Pasture was chosen because it can encompass a wide diversity of species such as grasses and legumes that may mitigate the effects of land on crop production. Admittedly, pasture may also refer to monocultures of alfalfa, and the ACI does not distinguish between mixed species pasture and pasture monocultures.

For each land class and crop type, annual maximum NDVI was used as a proxy for crop yield and processed using Google Earth Engine (Gorelick et al. 2017) with imagery originally from Landsat satellites (USGS 2019) between the years of 2011-2017. Landsat 7 was used for years 2011-2012 and Landsat 8 for 2013-2017, both with a spatial resolution of $30 \times 30 \mathrm{~m}$. The Landsat missions obtain satellite imagery on an approximately 16-day interval. NDVI is calculated with the equation:

$$
N D V I=\frac{\left(R_{N I R}-R_{r e d}\right)}{\left(R_{N I R}+R_{r e d}\right)}
$$

Where $\mathrm{R}_{\mathrm{NIR}}$ represents reflectance of near-infrared (NIR) light and $\mathrm{R}_{\mathrm{red}}$ representing reflectance of red light. For Landsat 
7, NIR light ranges from $0.77-0.90$ wavelengths and red light ranges from 0.63-0.69 wavelengths (USGS 2020). For Landsat 8, NIR light ranges from $0.85-0.88$ wavelengths and red light ranges from 0.64-0.67 wavelengths (USGS (a) 2020). NDVI measures light reflectance of the vegetation surface, and is also directly correlated with the photosynthetic capacity of plant canopies (Nguy-Robertson et al. 2012). NDVI values are bounded on a scale from -1 to +1 with values near -1 indicating bare ground or sparse vegetation with a low biomass (USGS (b) 2020). Conversely, values closer to +1 indicate highly productive vegetation with a high biomass (USGS (b) 2020). The presence of clouds can influence the NDVI value, therefore, pixels containing cloud cover were removed from the data, a process implemented using Band 9 (Cirrus band). Band 9 effectively detects high-altitude cloud contamination in the imagery to avoid any NDVI miscalculations (USGS 2019). Every year crops are harvested when their biomass is the greatest (highest NDVI), therefore, all NDVI Landsat imagery within a year was stacked and the maximum NDVI for every $30 \times 30 \mathrm{~m}$ pixel was extracted. The maximum NDVI layer was overlaid with agricultural land cover (crops corn, soybeans, pasture) and land quality (class 1 - 7) for each year at both the provincial and county scale (Figure 1). The average (mean) NDVI was calculated for each crop type within each land class at both the provincial and county scale. The resulting layer was used for all subsequent analyses. A summary of the data layers used in this study are listed and defined in Appendix A.

Ground-truthed agricultural yield values were obtained from the Ontario Ministry of Agriculture, Food and Rural Affairs (OMAFRA), accessed from the OMAFRA website for statistics on field crops where all crop yield data was available by county from 2004 to 2017. These data summarized the total crop yield in tonnes per hectare for a single county, with no coordinates specifying where the crop was harvested, and therefore no information on the quality of land the crop was grown on. These data were then compared against the small-scale satellite-derived NDVI values (maximum NDVI) to validate our method of using NDVI as a proxy of crop yield. The maximum NDVI values were then compared against the small-scale land quality values to test the predictions.

Variability in maximum yield within all 7 years across land quality and crop types was calculated using the coefficient of variance (CV) calculated with the following equation:

$$
C V(\%)=\left(\frac{\text { Standard deviation }}{\text { Mean }}\right) \times 100
$$

The CV measures the dispersion of the data-more specifically the variance around the mean of the dataset as a percent. The CV was used instead of standard deviation because the $\mathrm{CV}$ incorporates the mean of the dataset whereas standard deviation does not. Since the average maximum NDVI value changes across years, by incorporating the mean within the calculation, $\mathrm{CV}$ is able to account for these changes.
Crop yield means and variability were analyzed at both a provincial (Ontario) scale with years as the random factor and at the county scale with counties and years as the random factors. The county data layer was used to distinguish all county boundaries within southern Ontario. By analyzing crop yield at the county scale, there is an increase in the number of replicate samples from 7 replicates to 203 replicates ( 29 counties $\times 7$ years) potentially increasing the accuracy of the findings.

\section{Statistical Analysis}

Google Earth Engine (Gorelick et al. 2017) was used to process satellite imagery at the county and provincial scale. At the county scale, 29 counties were used as the replicate variables, and at the provincial scale, the 7 years were used as the replicate variables. Specifically, Landsat 7 and 8, Canada Land Inventory, Annual Crop Inventory, and the boundaries of Ontario counties layers were uploaded into Google Earth Engine (Table S1). Google Earth Engine was used to calculate the maximum NDVI values ("greenest pixel"; henceforth referred to as maximum NDVI) and the variability of the maximum NDVI values (henceforth referred to as the CV) across land quality and crop type for each year. These resulting values were analyzed statistically in $\mathrm{R}$ (version 1.1.456) (R Core Team 2018).

At the provincial scale, a mixed effect model was used to determine the ability for NDVI to be used as a proxy for crop yield, where average crop yield was predicted by NDVI (continuous) and crop type (categorical) as fixed factors and year as the random factor. At the county scale, county was used as an additional random factor using the lmer call within the lme4 package (Bates et al. 2015). At the provincial scale a repeated measures ANOVA was conducted to test the relationship between the maximum NDVI and crop yield. Year was used as a random factor and crop type and maximum NDVI as fixed factors within the $l m$ call.

At the county scale, a mixed effect model was used to determine the influence of land quality on the maximum NDVI (using the lmer call), where crop type (categorical) was used as a fixed factor and county and year as the random factors. As an exploratory analysis at the provincial scale, we examined how land quality influenced the maximum NDVI (using the $l m$ call), where crop type was a fixed factor and year was the random factor.

The influence of land quality on the CV response variable was evaluated using a linear model with land quality and crop type as the fixed factors. At the provincial scale, only year was used as the random factor, and at the county scale, both year and county were used as random factors. As an exploratory analysis, the maximum NDVI CV was compared within each county across 7 years using the lmer call. In the presence of significant interactions, post-hoc tests were conducted by evaluating relationships between predictor and response variables for individual crops. Significance was determined at $p \leq 0.050$. The significance of the maximum 
NDVI and land quality relationship was determined using the Anova call using a type 2 sum of squares (Fox \& Weisberg 2011).

\section{Results}

\section{NDVI is a good predictor of crop yield $(\mathrm{p}<0.001)$}

NDVI values were shown to be good predictors of crop yield, indicating that maximum NDVI is a good proxy for crop yield. At the provincial scale, higher crop yields were weakly associated with higher maximum NDVI values, but this relationship did not vary by crop type (Figure 2; $\mathrm{p}=0.07$; yield $($ tonnes $/$ ha $)=$ maximum NDVI $* 1.62+5.2$ ). At the county scale, greater maximum NDVI was also significantly related to higher crop yields, although the slope of this relationship varied by crop type (Figure 3; crop $\times$ yield interaction, $\left.\chi^{2}=24.02, \mathrm{p}<0.001\right)$.

\section{Maximum NDVI has small but significant decreases as land quality declines}

At the provincial scale, maximum NDVI did not vary by land quality $\left(\chi^{2}=0.00, p=0.991\right)$ nor was there an interaction between crop type and land quality (crop $\times$ land quality interaction, $\left.\chi^{2}=0.98, p=0.613\right)$ (Figure 4a).

At the county scale, however, maximum NDVI declined with lower land quality, but the strength of this relationship was dependent on crop type (Figure $\mathbf{4 b}$; land class $\times$ NDVI, $\chi^{2}=16.63, \mathrm{p}<0.001 ; \operatorname{corn} \chi^{2}=26.14, \mathrm{p}<0.001$; soybeans $\chi^{2}$ $=34.49, \mathrm{p}<0.001$; pasture $\chi^{2}=34.74, \mathrm{p}<0.001$ ). Looking between years, 2013, 2014 and 2015 showed signficantly lower NDVI with poorer land quality, however 2011 showed signficantly higher NDVI on poorer land quality (Figure 4).

Production is relatively stable across land qualities, but can be more variable at the county scale

Both the provincial and county scales showed no evidence of greater variability in crop production on poorer quality land, yet specific counties did show evidence of this relationship. At the provincial scale, the CV of NDVI was only dependent on crop type $\left(\chi^{2}=119.89, p<0.001\right)$ while there was no influence of land quality $\left(\chi^{2}=1.60, p=0.206\right)$ nor an interaction between land quality and crop type (Figure $5 \mathbf{a} ; \chi^{2}$ $=5.55, \mathrm{p}=0.062)$. We show that $\mathrm{CV}$ is highest for soybeans and lowest for pasture. At the county scale, the relationship between $\mathrm{CV}$ and land quality was dependent on crop type (crop $\times$ land quality interaction, $\left.\chi^{2}=10.18, p=0.006\right)($ Figure 5b). Results indicate that the CV remains relatively stable across land qualities for soybeans $\left(\chi^{2}=2.41, \mathrm{p}=0.120\right)$ and pasture $\left(\chi^{2}=0.29, p=0.587\right)$. Conversely, corn had higher $\mathrm{CV}$ on poor quality land $\left(\chi^{2}=4.37, p=0.037\right)$ although we recognize high overall variability (Figure $5 b$ ). When assessing these results at an even smaller scale (individual counties), majority of counties show no increase in the $\mathrm{CV}$ on poor land qualities ( $p>0.050)$. Conversely, 4 of the 29 do indicate a significant increase in the $\mathrm{CV}$ on poor land qualities (Figure 6; Brant $\mathrm{p}=0.050$; Haldimand-Norfolk $\mathrm{p}=0.010$; Peterborough $\mathrm{p}<0.001$; Hastings $\mathrm{p}<0.001$; Muskoka $\mathrm{p}<$ $0.001)$.

\section{Discussion}

Results from seven years of observational crop productivity analysis show small, but significant decreases in crop productivity with declining land quality at the county level scale. When accounting for all years together, maximum NDVI decreased by approximately 0.02 for all three crop types, where corn shows the most significant decline in productivity. When comparing the relationship between NDVI and land quality, individual years responded differently, where some years had a stronger relationship than others. The insignificant - and at times opposingrelationships evident in 2011 and 2012 suggest that decline in crop productivity may be dependent on the climatic factors occurring in that specific year (e.g. drought).

The findings of this study compliment previous studies that examine the effect of soil fertility on corn yield across 522 fields within 60 different farms throughout western Kenya (Tittonell et al. 2008). In the Tillonell et. al (2008) study, corn yields decreased by an average of $37 \%$ across all three sites in response to poor soil fertility. In comparison, we found only a $2 \%$ decrease in overall crop productivity on poor soil fertility. Differences in the scope (three individual farms versus across 107.6 million ha), as well as analytical approaches (wet chemistry and near infrared diffuse reflectance spectroscopy versus broad land type classifications; and mass-based productivity measurements versus reflectance-based measurements) may explain differences in the magnitude of yield reductions linked to poor soil fertility. Further, in scaling up from an individual farmscale to a provincial-wide scale, our study introduces larger variability in overall climate, which may dilute the magnitude of the direct influence of soil fertility on crop yields. This research also compliments studies looking at the effect of climate change on global crop yield where $3 \%$ of agricultural land growing corn showed a significant decrease in yield from 1975 to 2005 along with $37 \%$ of wheat area, $26 \%$ of corn area and $23 \%$ of soybean area showing significant yield stagnation (Deepak et al. 2012).

Future studies may expand crop type to include wheat that is evidently more susceptible to yield stagnation in the face of climate change and therefore, may be more susceptible to yield loss on poor quality land. Nonetheless, this study provides new evidence of large-scale land quality effects on crop yield, where significant crop yield losses were evident on poor quality land across Ontario. Interestingly, productivity declines on poor land quality are less prominent than initially expected, possibly due to an increase in fertilizer inputs since the Green Revolution (FAO 2015). Global fertilizer inputs 
have increased drastically over the past several decades (Matson et al. 1997), and while no spatially explicit data exists on fertilizer use across land quality gradients, poor quality land likely requires higher agrochemical inputs in order to produce yields equivalent to those seen on higher quality land. For the first time across Ontario, these results show that despite probable attempts to mitigate the negative impact of poor quality land on crop productivity, agricultural producers cannot overcome the biophysical limitations on crop yield. Despite the lack of data on land-specific fertilizer inputs, we can assume the majority of farms operate using synthetic fertilizer, thus this study concludes that the use of synthetic fertilizer cannot overcome the effect of land quality on crop yield.

No evidence of greater variability in crop productivity on poor quality land was seen at either county or provincial scale. Individual counties that showed evidence of greater variability in crop production on poor quality land may be a result of greater susceptibility to increasing variable weather as a result of climate change. Variable weather such as drought is known to have detrimental effects on crop yield and may also increase the negative effects of poor quality land on crop yield. This may be a potential explanation for why some counties show greater crop yield losses in comparison to other counties. Studies show that droughts occurring near critical developmental periods in April and May (near planting dates), and in August and September (near harvest dates) are cumulatively more detrimental to crop yield suggesting that drought effects on crop productivity are evidently more dependent on the month in which droughts occur, and less so the severity of the drought itself (Zipper et al. 2016). The results of this study show evidence of higher crop productivity on poorer quality land at the provincial scale during a substantial drought year. This contradictive result may be due to the majority of poor quality land being present in northern Ontario where droughts are also less likely to occur, whereas land in southern Ontario is of higher quality but is also more susceptible to the negative effects of drought. Future studies can incorporate the effect of drought on crop yield to investigate whether drought intensifies the effects of poor quality land on crop production.

Scaling down to an even smaller scale and evaluating the variability in crop productivity for specific counties rather than the province as a whole resulted in significant results. This suggests that there may be underlying variables effecting crop yield at the county scale that is not considered at the large scale of Ontario. At the provincial scale replicates were represented by the number of years, yet at the county scale replicates were represented by the number of counties. This suggests that greater detail may result in greater significance and therefore future research may require even more detail when measuring land quality, rather than using a general classification scheme. Soil characteristics such as texture, $\mathrm{pH}$, structure, and mineral particles are unique across small scales such as counties and these characteristics may need to be incorporated in the analysis when considering variability in crop productivity. For example, variability in crop yield for oats, rye and triticale is evident with varying soil characteristics (Usowicz \& Lipiec 2017). More specifically, there is a positive correlation between yield and topsoil water content, clay content in the subsoil, and cation exchange capacity, and a negative correlation with bulk density (Usowicz and Lipiec 2017). Future studies may consider investigating the effects of land quality on these small grains (oats, rye and triticale) to discern whether yield also varies with varying land quality. This suggests that land class may be too broad to classify land quality and that specific soil characteristics may be confounding variables in this study that impact how crop yield responds to climate change.

Evidence resulting from this study reveals that crop productivity decreases significantly on poor quality land, making efforts to maintain sufficient crop yield more demanding. The stable variability in crop productivity observed across the variety of land qualities also raises the question of whether growers are attempting to maximize crop yield on poor quality land by inputting more fertilizer to compensate for a loss in soil fertility. This mitigates the negative effects on crop yield associated with poor quality land that normally would suffer in productivity and results in an overall stabilizing effect across all land qualities.

Understanding how crop yields are influenced by land quality, irrespective of management interventions, may allow agricultural producers to refine crop production techniques. For instance, intensifying production on high quality land may result in higher yield gains and greater production stability as compared to simply expanding production onto less fertile lands. Apart from the ability to produce food crops, marginal land may be better suited for ecosystem services and other conservation efforts. For example, there are associated benefits of planting prairie strips to alleviate biodiversity loss in corn and soybean croplands (Schulte et. al 2017). Replacing 10\% of cropland with prairie strips may result in increased insect taxa, pollinator, and native bird abundance and richness (Schulte et. al 2017). Along with increased biodiversity, total water runoff may be reduced by $37 \%$ resulting in 20 times more soil and 4.3 times more phosphorus (Schulte et. al 2017). By increasing the conservation efforts on agricultural land, this can enhance the overall health and reduce degradation of the land that agricultural producers highly rely on.

This study addressed the importance of prioritizing agricultural production on high quality land with the future demand to double crop production with the simultaneous detrimental effects of climate change on yield, along with the reduction in high quality land availability with increasing development as a result of human population growth. Understanding differential crop productivity responses to land quality can help producers mitigate crop losses to climatic variation, equally stabilize profits and food availability, while simultaneously benefitting from converting marginal land to conservation land. 


\section{Acknowledgements}

I would like to thank the University of Guelph for the opportunity to perform research as an undergraduate student.

\section{References}

Agriculture and Agri-Food Canada (AAFC). (2009). ISO 19131 Annual Crop Inventory (ACI)- Data Product Specification (Revision A). Government of Canada.

Agriculture and Agri-Food Canada (AAFC). (2013). ISO 19131 Canada Land Inventory (CLI)- Data Product Specification (Revision A). Government of Canada.

Aerial Video Services (AVS). (2019). Crop Health Analysis. Viewed on January 30, 2019 from https://aerialvideoservices.net/services/crop-healthanalysis/

Alexandratos, N., and J. Bruinsma. (2012). World agriculture towards 2030/2050: the 2012 revision. 12-03, Agricultural Development Economics Division, Food and Agriculture Organization of the United Nations.

Arvidsson, J. (1998). Influence of soil texture and organic matter content on bulk density, air content, compression index and crop yield in field and laboratory compression experiments. Soil and Tillage Research. 49(1-2):159-170.

Bates, D., Machler, M., Bolker, B.M., Walker, S.C. (2015). Fitting linear mixed-effects models using lme4. $J$. Stat. Softw. 67:1-48.

Department of Forestry, Canada (DOF). (1965). The Canada Land Inventory (Report No. 1). Ottawa, Ontario: Department of Forestry, Canada.

Deepak, R.K., Ramankutty, N., Mueller, N.D., West, P.C. and Foley, J.A. (2012). Recent patterns of crop yield growth and stagnation. Nature Communications. 3(1293):1-7.

Deepak, R.K., Gerber, J.S., MacDonald, G.K. and West, P.C. (2015). Climate variation explains a third of global crop yield variability. Nature Communications. 6:5989.

Food and Agriculture Organization of the United Nations (FAO) (2015). World fertilizer trends and outlook to 2018. Food and Agriculture Organizations of the United Nations.
Fox, J., Weisberg, S. (2011). An R companion to applied regression, second edition. Sage, Thousand Oaks, CA

Gastal, F., Lemaire, G., Durand, J.L. and Louarn, G. (2015). Quantifying crop responses to nitrogen and avenues to improve nitrogen-use efficiency. App. Gen. Improve. Agro. pp. 161-206.

Gorelick, N., Hancher, M., Dixon, M., Ilyushchenko, S., Thau, D., Moore, R. (2017). Google Earth Engine: planetary-scale geospatial analysis for everyone. Remote Sens. Environ. 202:18-27 doi:10.1016/j.rse.2017.06.031

Johnson, M.D. (2011). Crop yield forecasting on the Canadian prairies by satellite data and machine learning methods. The University of British Columbia.

Lobell, D.B. and M. B., Burke. (2008). Why are agricultural impacts of climate change so uncertain? The importance of temperature relative to precipitation. Environmental Research Letters, 3:034007.

Lobell, D. B., Schlenker, W. \& Costa-Roberts, J. (2011). Climate trends and global crop production since 1980. Science. 333:616-620.

Matson, P.A., Parton, W.J., Power, A.G. and Swift, M.J. (1997). Agricultural intensification and ecosystem properties. Science, 277(5325):504-509.

Nguy-Robertson, A., Gitelson, A., Peng, Y., Vina, A., Arkebauer, T. and Rundquist, D. (2012). Green leaf area index estimation in maize and soybean: combining vegetation indices to achieve maximal sensitivity. Agronomy Journal. 104(5): 1336-13

R Core Team. (2018). R: A language and environment for statistical computing. R Foundation for Statistical Computing, Vienna, Austria

Ressia, J.M, Mendivil, G., Balbuena, R.H., Chidichimo, O. (1998). Root growth and grain yield of corn in relation to tillage systems. In Proceedings of the IV CADIR Argentine Congress on Agricultural Engineering. 1:98-104

Schlenker, W., D. B. Lobell, (2010). Robust negative impacts of climate change on African agriculture. Environ. Res. Lett. 5, 014010.

Schulte, L.A., Niemi, J., Helmers, M.J., Liebman, M., Arbuckle, J.G., James, D.E. et. Al. (2017). Prairie strips to improve biodiversity and the delivery of multiple ecosystem services from corn-soybean 
cropland. PNAS. 114(24):11247-11252.

Seddigh, M., \& Jolliff, G. D. (1984). Physiological responses of field-grown soybean leaves to increased reproductive load induced by elevated night temperatures. Crop Science, 24, 952-957. doi: $10.2135 /$ cropsci1984.0011183X002400050031 $\underline{x}$

Statistics Canada. (2016). The changing landscape of Canadian metropolitan areas. Retrieved from https://www150.statcan.gc.ca/n1/pub/16-201$\mathrm{x} / 2016000 /$ app-ann b-eng.htm

Tilman, D., J. Knops, D. Wedin, P. Reich, M. Ritchie, and E. Siemann. 1997. The influence of functional diversity and composition on ecosystem processes. Science, 277:1300-1302.

Tilman, D., D. Wedin and J. Knops. 1997. Productivity and sustainability influenced by biodiversity in grassland ecosystems. Nature, 379:718-720.

Tittonell, P., Shepherd, K.D., Vanlauwe, B. and Giller, K.E. (2008). Unraveling the effects of soil and crop management on maize productivity in smallholder agricultural systems of western Kenya- An application of classification and regression tree analysis. Agriculture, Ecosystems and Environment. 123:137-150.

Toshichika, I. and Navin, R. (2016). Changes in yield variability of major crops for 1981-2010 explained by climate change. Environmental Research Letters, 11:034003

Usowicz, B. and Lipiec, J. (2017). Spatial variability of soil properties and cereal yield in a cultivated field on sandy soil. Soil and Tillage Research. 174:241-250.

USGS. Retrieved from https://landsat.usgs.gov/landsat- 8 on March 20, 2019.

USGS (a). Retrieved from https://www.usgs.gov/faqs/whatare-best-landsat-spectral-bands-use-my-research?qtnews_science_products $=0 \#$ qtnews_science products on August 21, 2020.

USGS (b). Retrieved from https://www.usgs.gov/landresources/nli/landsat/landsat-normalized-differencevegetation-index?qt-

science_support page related con $=0 \#$ qtscience support page related con on August 21, 2020

Vieira, S.R. and Gonzalez, A.P. (2003). Analysis of the spatial variability of crop yield and soil properties in small agricultural plots. Bragantia, Campinas. 62 (1):127-138.

Young, A. Is there really spare land? A critique of estimates of available cultivable land in developing countries. Environment, Development and Sustainability 1, 318, doi:10.1023/a:1010055012699 (1999).

Wescott, P. \& Jewison, M. (2013). Weather effects on expected corn and soybean yields. USDA Economic Research Service. FDS-13G-01:1-33.

Zhu, P., Jin, Z., Zhuang, Q., Ciais, P., Bernacchi, C., Wang, $X$. , et. Al. (2018). The important but weakening maize yield benefit of grain filling prolongation in the US Midwest. Glob. Change Biol. 24:4718-4730.

Zipper, S.C., Qiu, J. and Kucharik, C.J. (2016). Drought effects on US maize and soybean production: spatiotemporal patterns and historical changes. Environmental Research Letters. 11:094021

Wright, C. K., and M. C. Wimberly. 2013. Recent land use change in the Western Corn Belt threatens grasslands and wetlands. Proceedings of the National Academy of Sciences of the United States of America 110:4134-4139. 


\section{Tables and Figures}

Table 1. Description of the Canada Land Inventory soil classifications on a scale of 1 to 7.

\begin{tabular}{|c|l|}
\hline Land Class & Description \\
\hline 1 & No significant limitations \\
\hline 2 & Moderate limitations and require moderate conservation practices. \\
\hline 3 & Moderately/severe limitations and require special conservation practices. \\
\hline 4 & Severe limitations and land requires special conservation practices and careful management. \\
\hline 5 & Very severe limitations, restricted capability to produce yields, and require improvement practices. \\
\hline 6 & Unsuited for cultivation, but are suitable to use for pasture. \\
\hline 7 & No capability for arable culture or permanent pasture. \\
\hline
\end{tabular}

A.

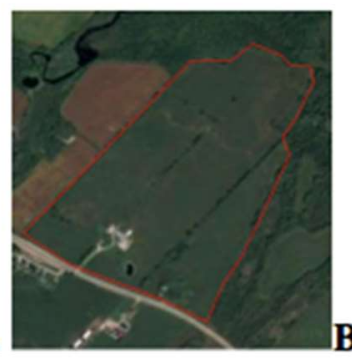

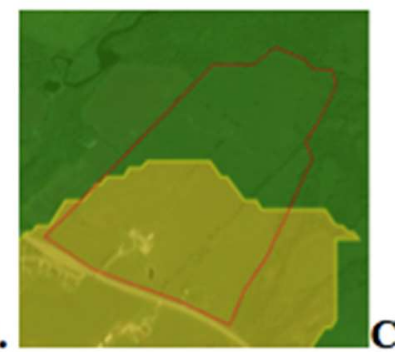

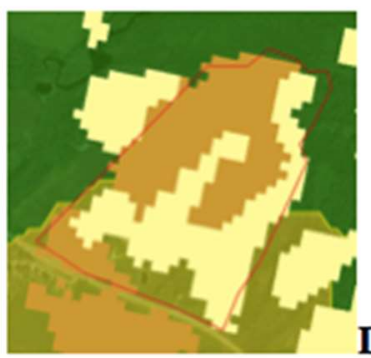

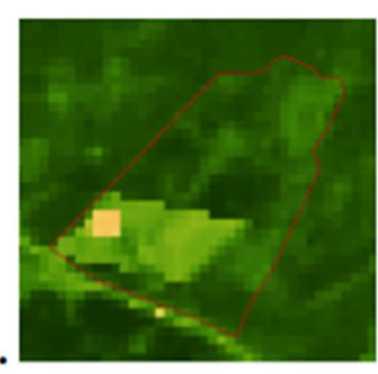

D.

Figure 1. Methods summary showing layers which were stacked for data analysis on a boundary outlined in red: $(A)$ Location of example field as seen from Google Maps. (B) Canada Land Inventory layer showing land quality (green= class 2; yellow= class 4) (C) Annual Crop Inventory layer specifying the crop type, computed on an annual basis (beige= corn; orange= soybean) (D) maximum NDVI computed for each growing season as measured by Landsat 7 (2011-2012) or Landsat 8 (2013-2017). Location of this site is latitude -80.75996 longitude 44.00155 . 


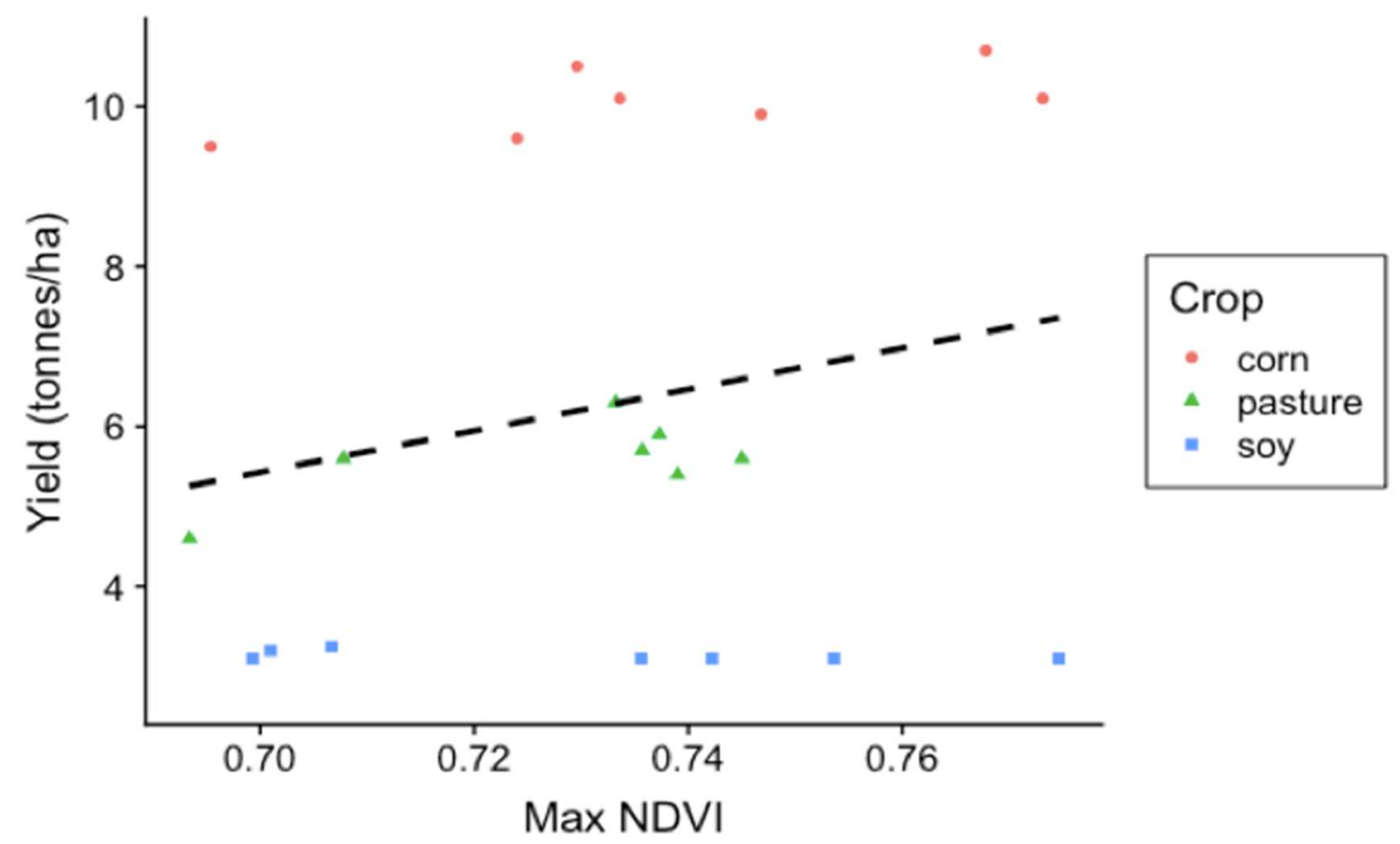

Figure 2. Relationship between maximum NDVI and total yield at the provincial scale for all three crop types; corn (red), pasture (blue) and soybean (green) from 2011 to 2017. The black dashed line represents the general trend $(p=0.07)$.

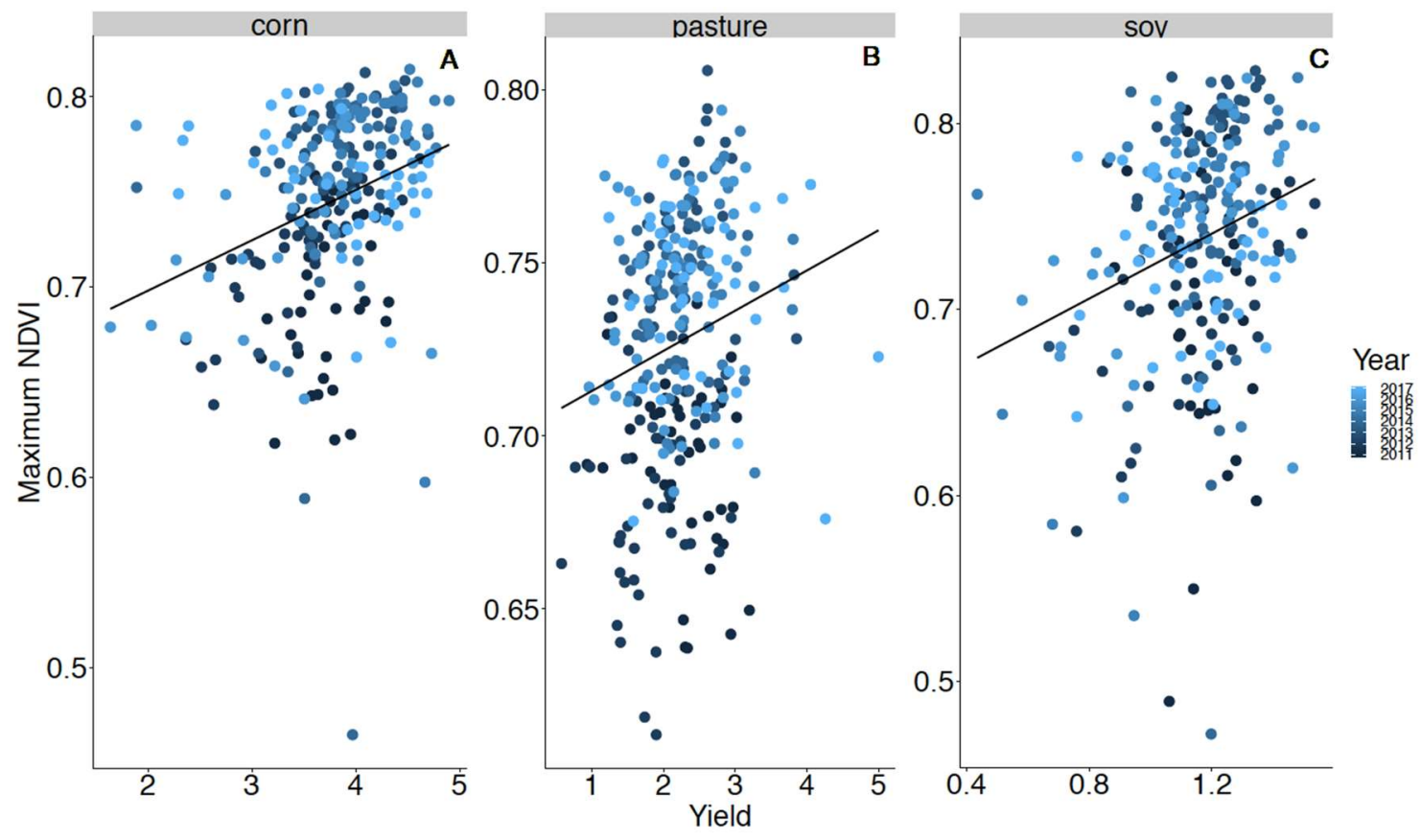

Figure 3. Relationship between maximum NDVI and total yield at the county scale for all three crop types; corn (A.), pasture (B.) and soybean (C.) from 2011 to 2017. Point colour indicates year (ranging from dark blue $=2011$ to light blue $=2017$ ), and fitted lines represent the significant relationship between crop yield and NDVI. 

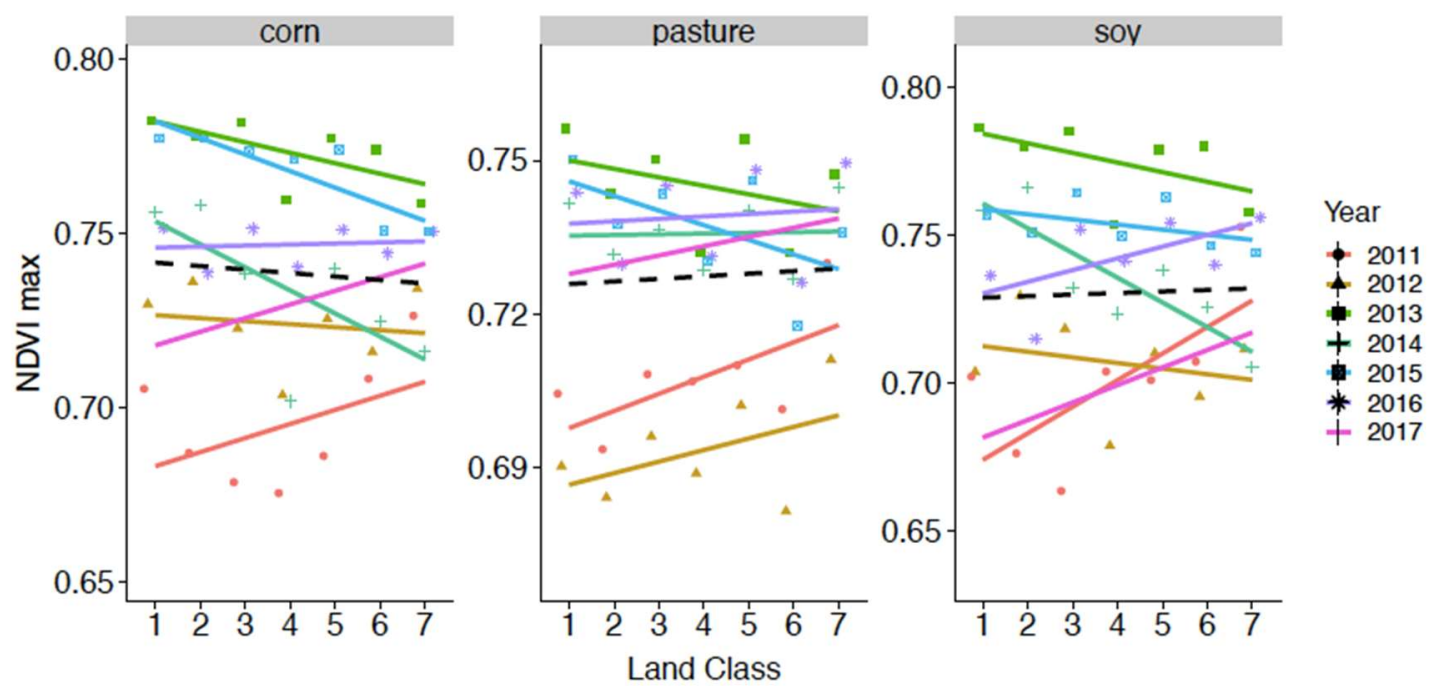

A.
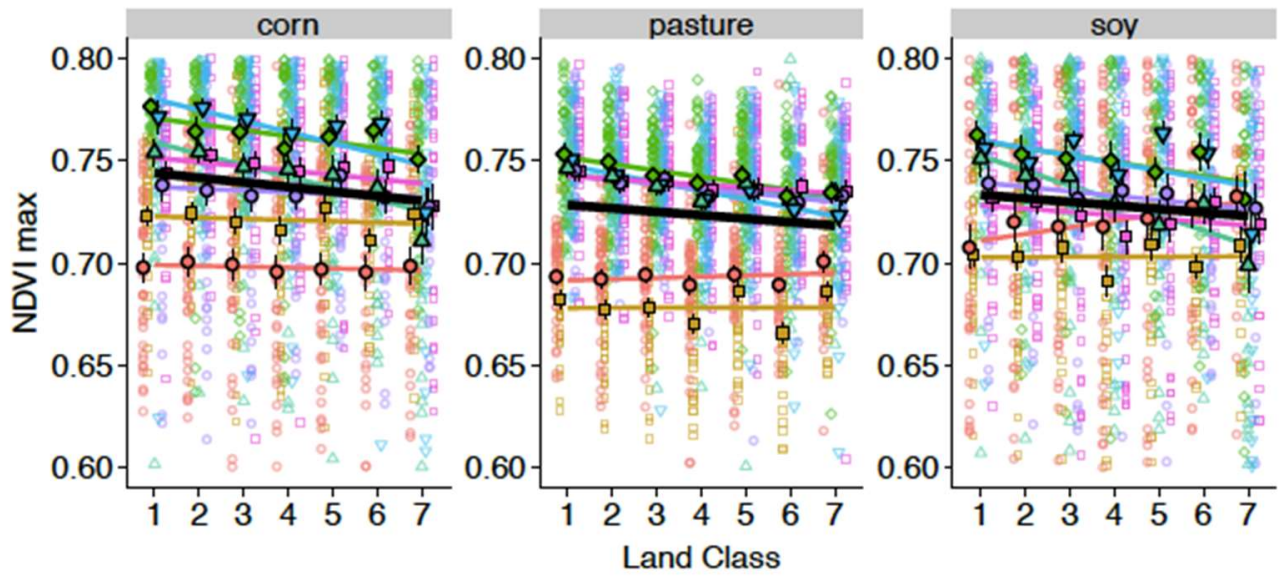

Year

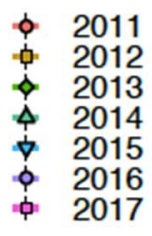

B.

Figure 4. Effect of land quality (land class where $1=$ good quality land and $7=$ poor quality land) on crop productivity (maximum NDVI) where crop is differentiated by each panel (A.) provincial scale where each shape/colour indicates year and the black line indicates the general relationship of the whole dataset (B.) county scale where shape/colour indicates year, while transparency of each colour indicates a different county. Coloured lines show the relationship between NDVI and land quality for each individual year and black lines show the overall relationship between NDVI and land quality for all years together. Significant linear relationships $(p<0.050)$ are shown with a solid black line for panel B. In panel A the dashed black lines represent the general trend across all years. 

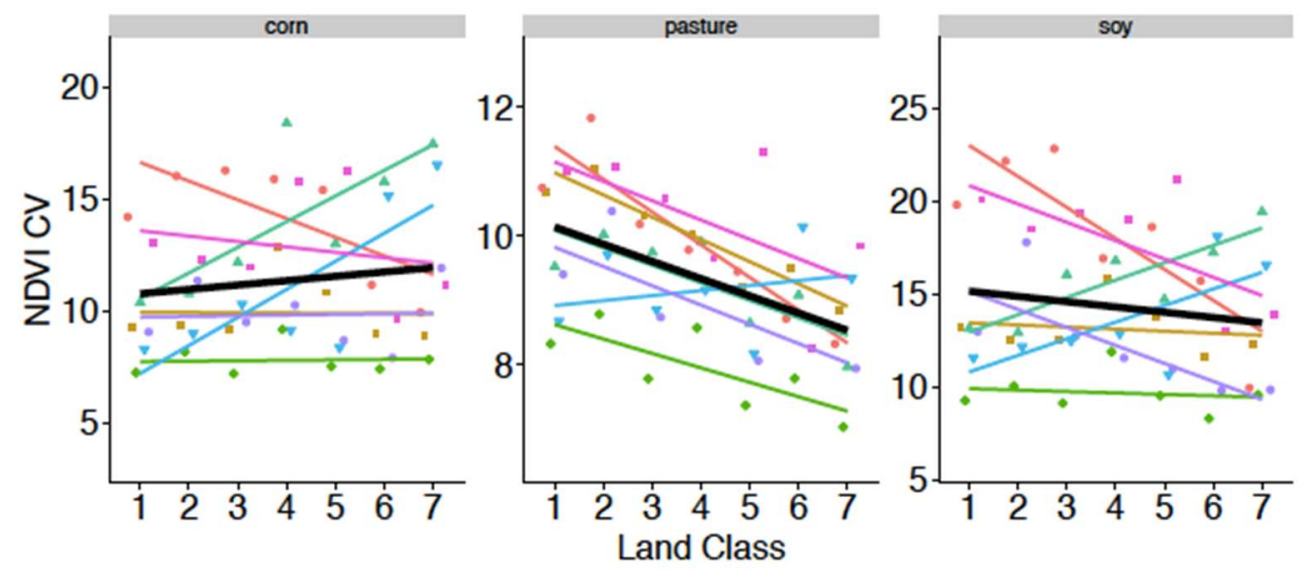

Year
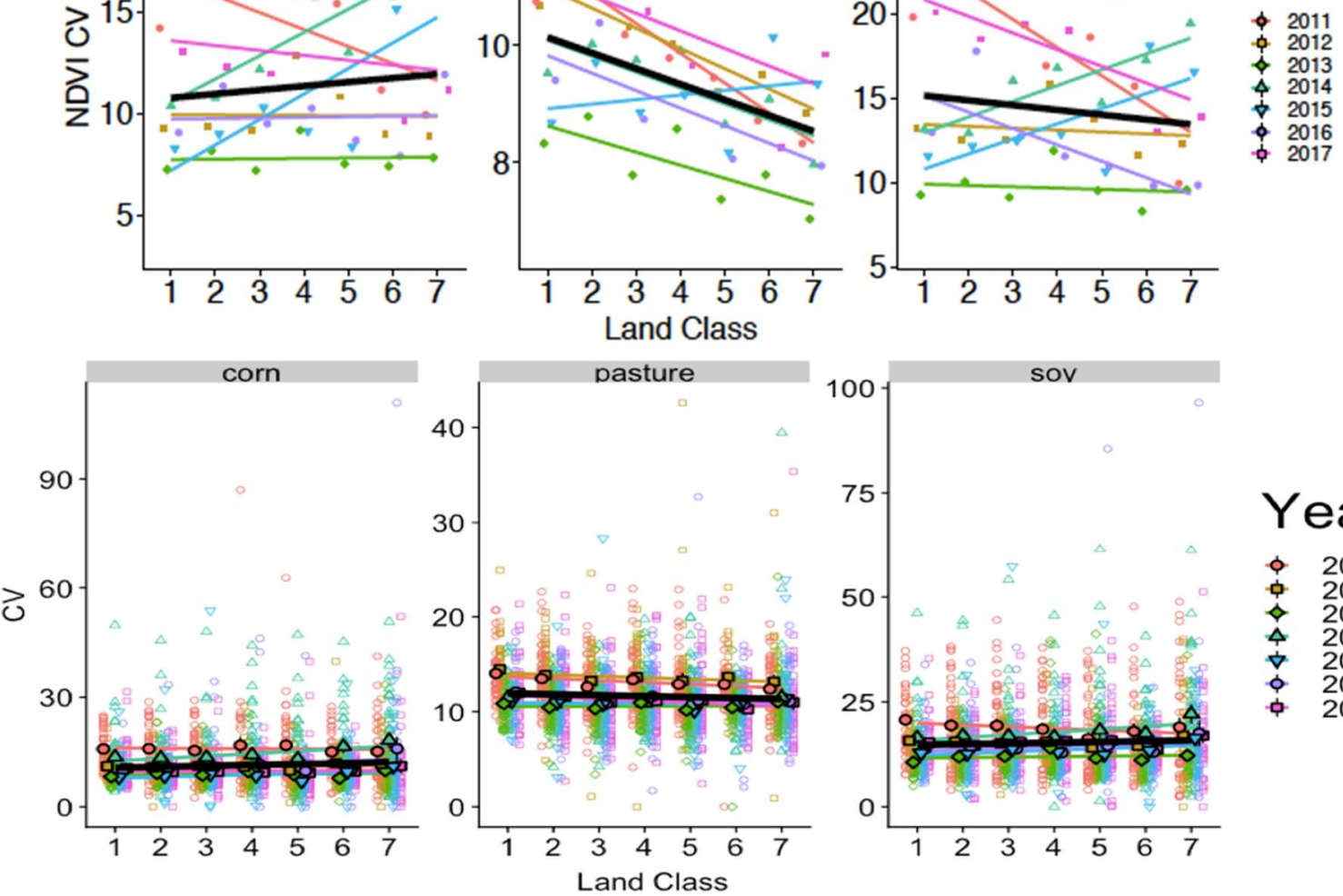

\section{Year}

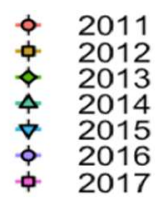

Figure 5. Effect of land quality (land class where $1=$ good quality land and $7=$ poor quality land) on variability in crop productivity (CV of NDVI) where crop is differentiated by each panel (A.) provincial scale where each shape/colour indicates year and the black line indicates the general relationship of the whole dataset (B.) county scale where shape/colour indicates year, while transparency of each colour indicates a different county. Coloured lines show the relationship between $\mathrm{CV}$ and land quality for each individual year and black lines show the overall relationship between $\mathrm{CV}$ and land quality for all years together. 
Small, But Significant Declines In Crop Productivity On Low Fertility Soils (Ramirez, Esch, \& MacDougall)
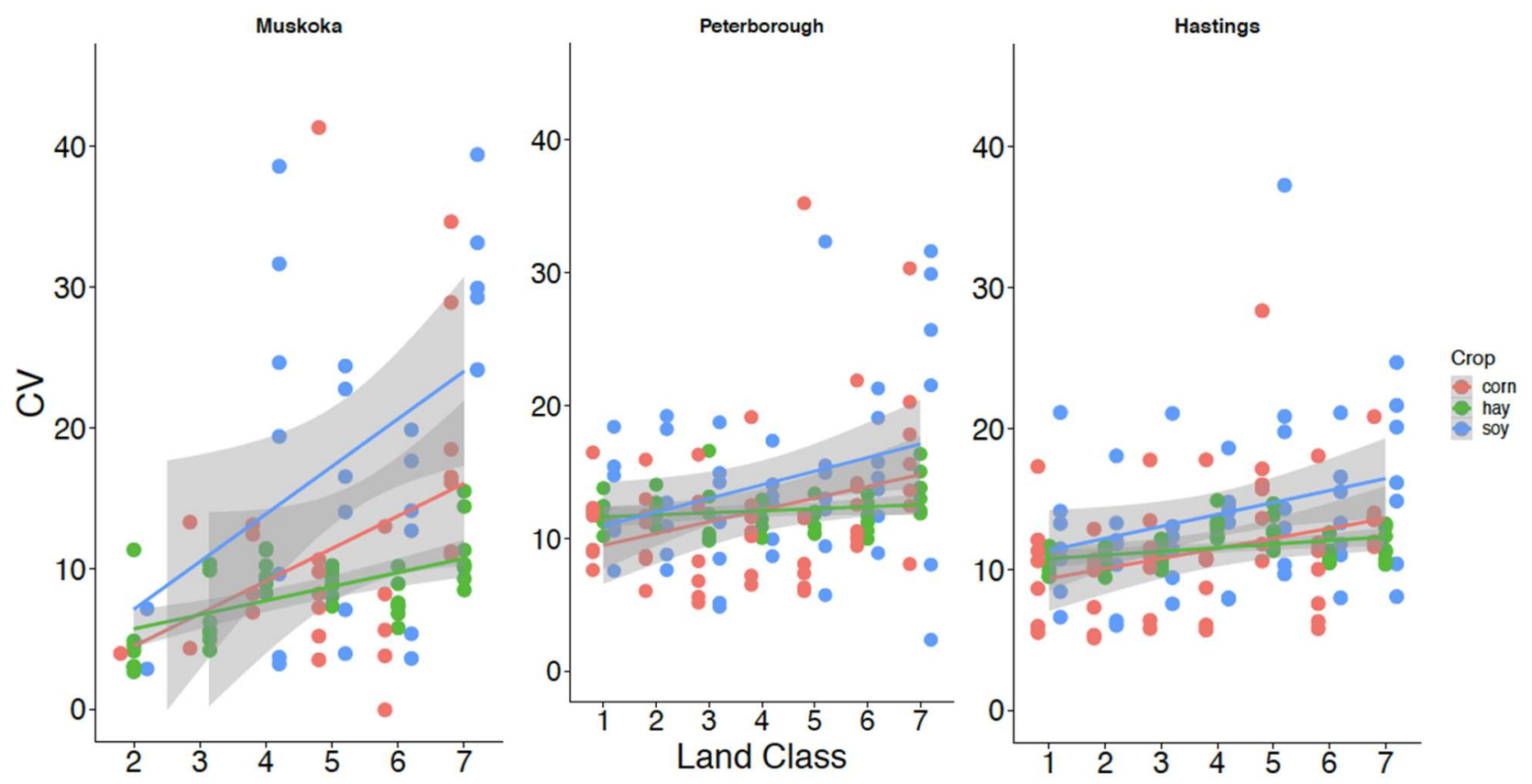

Figure 6. Effect of land quality (land class where 1= good quality land and $7=$ poor quality land) on variability in crop productivity (CV of NDVI) for select counties (Muskoka, Peterborough and Hastings) from 2011 to 2017. Crop is differentiated by colour (corn=red, pasture=green and soybean=blue). Each individual line shows the relationship between $\mathrm{CV}$ and land quality for each individual crop type. 


\section{Appendix A}

Table S1. Summary of all data layers used in this study including the data layer names, data source, and a brief data description.

\begin{tabular}{|l|l|l|l|l|}
\hline Data Layer Name & Source & Description & $\begin{array}{l}\text { Spatial } \\
\text { Resolution }\end{array}$ & Years used \\
\hline Annual Crop Inventory & $\begin{array}{l}\text { Agriculture and Agri- } \\
\text { Food Canada }\end{array}$ & $\begin{array}{l}\text { Annual crop type digital maps of } \\
\text { Canada that update every year. }\end{array}$ & 30 m pixels & $2011-2017$ \\
\hline Canada Land Inventory & $\begin{array}{l}\text { Agriculture and Agri- } \\
\text { Food Canada }\end{array}$ & $\begin{array}{l}\text { Maps the varying potential of } \\
\text { specific areas in Canada for } \\
\text { agricultural production. }\end{array}$ & $1: 250,000$ & $2011-2017$ \\
\hline $\begin{array}{l}\text { Canada Census } \\
\text { Subdivisions }\end{array}$ & Statistics Canada & $\begin{array}{l}\text { Digital boundary files of census } \\
\text { subdivisions (eg. counties) across } \\
\text { Canada. }\end{array}$ & $\begin{array}{l}\text { N/A } \\
\text { (vector) }\end{array}$ & $2011-2017$ \\
\hline Landsat 7 & $\begin{array}{l}\text { United States Geological } \\
\text { Survey }\end{array}$ & $\begin{array}{l}\text { Global archive of up-to-date and } \\
\text { cloud free satellite photos (launched } \\
\text { in 1999) }\end{array}$ & 30 m pixels & $2011-2012$ \\
\hline Landsat 8 & $\begin{array}{l}\text { United States Geological } \\
\text { Survey }\end{array}$ & $\begin{array}{l}\text { Global archive of up-to-date } \\
\text { and cloud free satellite photos } \\
\text { (launched in 2013) }\end{array}$ & 30 m pixels & $2013-2017$ \\
\hline
\end{tabular}

